\title{
Effect of the Distribution System on Drinking Water Quality
}

\author{
A. Grünwald, B. Št’astný, K. Slavíčková, M. Slavíček
}

The overall objective of this paper is to characterise the main aspects of water quality deterioration in a distribution system. The effect of residence time on chlorine uptake and the formation and evolution of disinfection by-products in distributed drinking water are discussed.

Keywords: drinking water, distribution system, chlorine uptake, THM and HAA formation.

\section{Introduction}

In recent years attention has been drawn to understanding, characterising and predicting water quality behaviour in drinking water distribution systems. These systems act as large-scale chemical and biological reactors with a considerable residence time. Improper design and operation may result in water of diminished quality in terms of increased water age, reduced disinfectant residual, increased growth of disinfectant by-products and bacterial levels, and may impact the level of compliance with current and impending water-quality regulations [1]. In the past, several authors have proposed algorithms for use in simulating the spatial and temporal variations in distribution system water quality.

\section{Experimental part}

This study concentrates on changes in water quality transport in the pipelines that take drinking water from WTP Plav to the town of Tábor and to the towns and villages that lie on this route [2]. The length of these pipelines is about $80 \mathrm{~km}$. The material of the pipelines is steel without any type of coating. They carry about $285 \mathrm{l} \cdot \mathrm{s}^{-1}$ from WTP Plav. There are six reservoirs along the pipelines, at various intervals, with a total capacity of about $48000 \mathrm{~m}^{3}$.

The samples for this study were taken from six locations along the pipelines travelling towards Tábor (Fig. 1).

Two methods were used to predict the decrease in residual chlorine in the distributed water.

\section{Modeling of chlorine decay}

The first method for the decrease in chlorine in the bulk flow is based on first order kinetics [3]:

$$
c_{\mathrm{t}}=c_{0} \cdot \mathrm{e}^{-k_{1} t}
$$

where $c_{\mathrm{t}}$ is the chlorine concentration in time $t$, in $\mathrm{mg} \cdot \mathrm{l}^{-1}$,

$c_{0} \quad$ chlorine concentration in time $t=0$, in $\mathrm{mg} \cdot \mathrm{l}^{-1}$,

$t$ time in days,

$k_{1} \quad$ first order decay coefficient in $\mathrm{d}^{-1}$.

The chlorine decay coefficient $k_{1}$ calculated from the values of chlorine concentrations measured in the period 1997-2000 ranged from $0.252 \mathrm{~d}^{-1}$ to $1.336 \mathrm{~d}^{-1}$ and their coefficient of correlation varied from 0.637 to 0.999 . A value lower than 0.9 was stated only 5 times.

The second method for modelling possible chlorine loss in a pipe [4] combines the effect of bulk reaction, wall reaction and mass transfer. The overall rate of chlorine decay can be expressed as follows:

$$
\Theta_{\mathrm{c}}=-k_{\mathrm{b}}-\frac{k_{\mathrm{f}}}{R_{\mathrm{H}}}\left(c-c_{\mathrm{w}}\right)
$$

where $\Theta \quad$ is the rate of chlorine decay in $\mathrm{mg} \cdot \mathrm{l}^{-1} \cdot \mathrm{d}^{-1}$,

$k_{\mathrm{b}} \quad$ first order decay coefficient in $\mathrm{d}^{-1}$,

$c$ chlorine concentration in bulk flow in $\mathrm{mg} \cdot \mathrm{l}^{-1}$,

$k_{\mathrm{f}} \quad$ mass transfer coefficient in $\mathrm{m} \cdot \mathrm{d}^{-1}$,

$R_{\mathrm{H}}$ hydraulic radius in $\mathrm{m}$,

$c_{\mathrm{w}} \quad$ chlorine concentration at the pipe wall in $\mathrm{mg} \cdot \mathrm{l}^{-1}$.

The coefficient of chlorine uptake calculated by the second method includes two factors - chlorine uptake in bulk flow, and chlorine transfer from the bulk liquid to the wall with the subsequent reaction with biofilm and consumption of chlorine in the corrosion process. The calculated values of $k_{\mathrm{b}}$ for the whole period 1997-2000 ranged from 0.00 to $1.336\left(\mathrm{~d}^{-1}\right)$ and for the constants $k_{\mathrm{W}_{1}}$ (constant of chlorine uptake on the wall) from 0.828 to $1.000\left(\mathrm{~m} \cdot \mathrm{d}^{-1}\right)$. A coefficient of correlation lower than 0.9 was stated only in one case. This

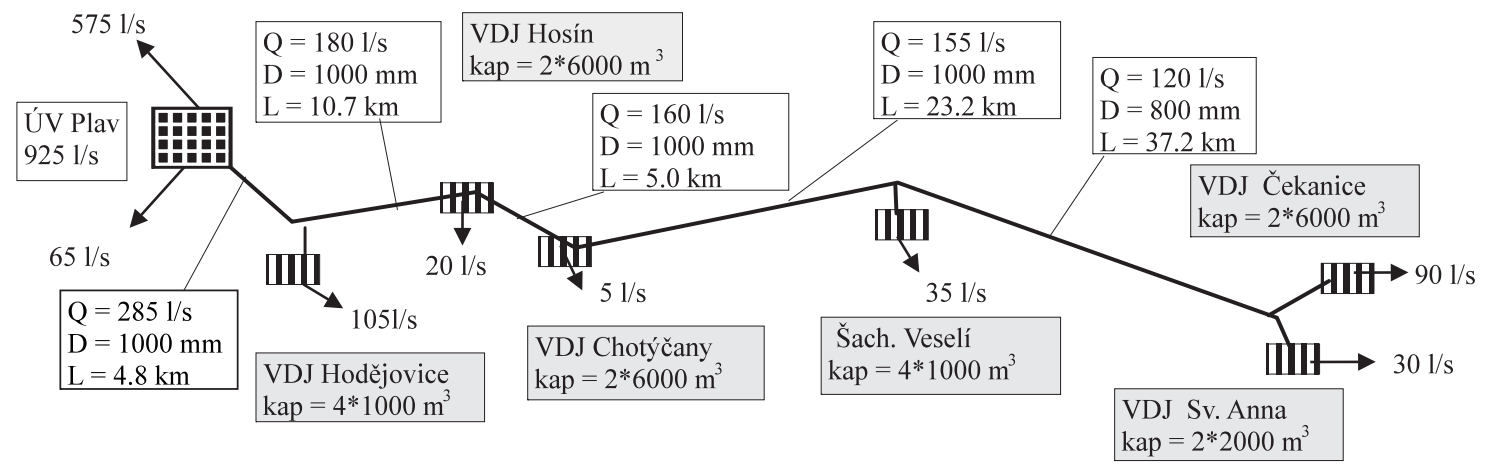

Fig. 1: The samples for this study were taken from six locations along the pipelines travelling to the town of Tábor 
model demonstrated higher similarity to the measured values than the previous model.

It was shown that the piping procedure has an important effect on the residence time in different parts of the distribution system. Piping from WR Hosín II into WR Chotýčany take place during the night and is complete by 5 o'clock in the morning. The residence time difference between the samples taken from WR Chotýčany and WR Hosín II is about 5 hours.

The decay of active chlorine with increasing residence time in the distribution system is given in Fig. 2.

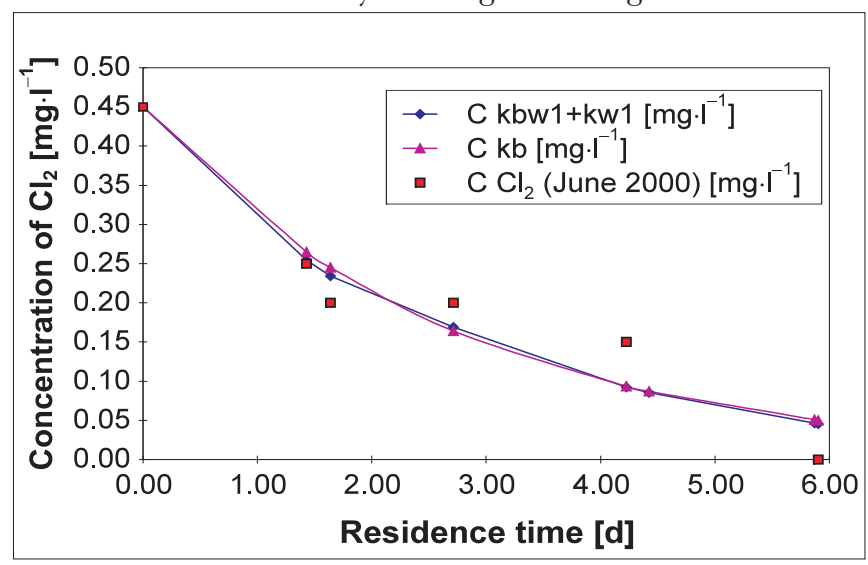

Fig. 2: Decay of active chlorine residual as a function of residence time

The concentration of chlorine active in the effluent from WTP Plav or WR Hosín II ranged during the whole period between 0.15 and $0.85 \mathrm{mg} \cdot \mathrm{l}^{-1}$. In the influent to WR Sv. Anna and Veselí $\mathrm{n} / \mathrm{L}$ the concentration of active chlorine was zero. The residence time at the end of the pipeline (WR Sv. Anna) was between 4.56 and 7.26 days. The average retention time was 5.85 days.

\section{Deposition formation}

Previous research on the south Bohemian transport pipeline has shown that deposits formed from particles of various origins and size can under specific conditions deteriorate the quality of distributed drinking water [5]. As a consequence of the resuspension of these deposits there is a rise in the consumption of active chlorine and in the formation of disinfection by-products in the bulk flow.

In our research a number of deposits were sampled from different sampling points along the transport pipeline. Sample 1 comes from the shaft behind WR Hosín, Sample 2 from the shaft behind WR Chotýčany, Sample 3 from the shaft before WR Zlukov and Sample 4 from the shaft before WR Sv. Anna. The characteristics of these samples are given in Table 1.

The characteristics of the deposits given in Table 1 show no dependency on sampling point.

The content of suspended solids varied between 353 and $892 \mathrm{mg} \cdot \mathrm{l}^{-1}$, an the content of volatile solids was rather low (1.3-3.1\% of suspended solids). The main part of the suspended solids consisted of iron. Its content ranged between 84.5 and $215 \mathrm{mg} \cdot \mathrm{g}^{-1}$ (8.45-21.5\% of total suspended solids). The highest values were found in Samples 1 and 2. The content of other metals, e.g., manganese (0.28-0.67\%), nickel $(0.01-0.04 \%)$ and zinc $(0.05-0.007 \%)$ was much lower.
Table 1: Characteristics of deposits from the pipeline WTP Plav - town of Tábor

\begin{tabular}{|c|c|c|c|c|c|}
\hline \multicolumn{2}{|c|}{ Sample No. } & 1 & 2 & 3 & 4 \\
\hline Total solids & {$\left[\mathrm{mg} \cdot \mathrm{l}^{-1}\right]$} & 1103 & 535 & 630 & 833 \\
\hline Volatile solid & {$\left[\mathrm{mg} \cdot \mathrm{l}^{-1}\right]$} & 84 & 35 & 81 & 119 \\
\hline \multicolumn{2}{|c|}{ Nonvolatile solids $\left[\mathrm{mg} \cdot \mathrm{l}^{-1}\right]$} & 1019 & 500 & 549 & 714 \\
\hline \multirow{3}{*}{\multicolumn{2}{|c|}{$\begin{array}{ll}\text { Suspended solids } & {\left[\mathrm{mg} \cdot \mathrm{l}^{-1}\right]} \\
\text { Volatile solids } \quad\left[\mathrm{mg} \cdot \mathrm{l}^{-1}\right] & \text { Nonvolatile solids }\left[\mathrm{mg} \cdot \mathrm{l}^{-1}\right]\end{array}$}} & 892 & 353 & 439 & 627 \\
\hline & & 65 & 11 & 31 & 71 \\
\hline & & 827 & 342 & 408 & 556 \\
\hline \multirow{2}{*}{$\begin{array}{l}\text { COD }_{\mathrm{Mn}} \\
\text { usp. s. }\end{array}$} & {$\left[\mathrm{mg} \cdot \mathrm{l}^{-1}\right]$} & 21.0 & 5.8 & 7.4 & 19.0 \\
\hline & {$\left[\mathrm{mg} \cdot \mathrm{l}^{-1}\right]$} & 16.1 & 1.4 & 3.0 & 7.0 \\
\hline \multirow[t]{2}{*}{$\mathbf{F e}$} & {$\left[\mathrm{mg} \cdot \mathrm{l}^{-1}\right]$} & 215.4 & 214.1 & 153.0 & 84.5 \\
\hline & {$[\%]$} & 21.5 & 21.4 & 15.3 & 8.45 \\
\hline \multirow[t]{2}{*}{ Mn } & {$\left[\mathrm{mg} \cdot \mathrm{l}^{-1}\right]$} & 3.0 & 2.8 & 4.2 & 6.70 \\
\hline & [\%] & 0.3 & 0.28 & 0.42 & 0.67 \\
\hline \multirow[t]{2}{*}{$\mathbf{N i}$} & {$\left[\mathrm{mg} \cdot \mathrm{l}^{-1}\right]$} & 0.16 & 0.10 & 0.18 & 0.39 \\
\hline & {$[\%]$} & 0.016 & 0.01 & 0.02 & 0.04 \\
\hline TG & {$[\%]$} & 4.81 & 7.85 & 8.50 & 7.02 \\
\hline IC & {$[\%]$} & 1.72 & 7.77 & 7.62 & 3.81 \\
\hline TOG & {$[\%]$} & 3.09 & 0.08 & 0.88 & 3.21 \\
\hline
\end{tabular}

Sedimentation analysis was used to analyse the characteristics of deposit suspension. From the measured values the sedimentation rates of particles and their proportion in the suspension were calculated. The comparison of the sedimentation curves is given in Fig. 3 .

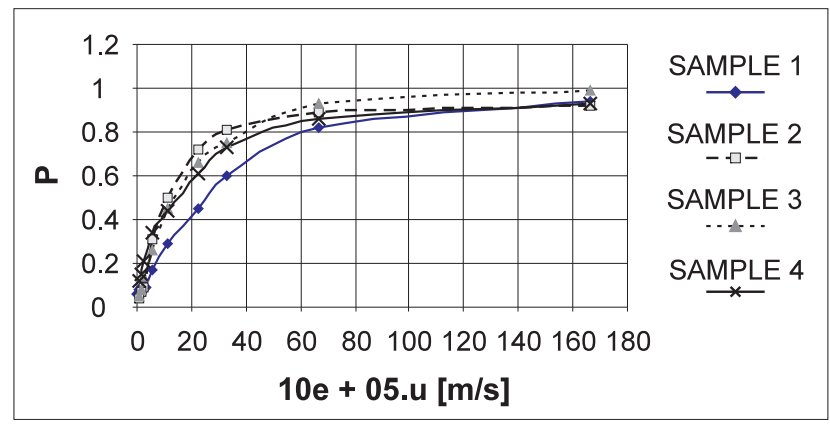

Fig. 3: Sedimentation curves

The results of the sedimentation show that the biggest proportion of the particles deposited at higher rates were in Sample 1, sampled from the shaft near WTP Plav. The reason for this could be the high iron content. The sedimentation curves of Samples 2, 3 and 4 were similar, but a larger proportion with good sedimentation was found in Sample 4. This sample contained the highest content of suspended solids and the highest content of TOC.

Fig. 2 shows that the deposits consisted mainly of particles that sediment at low rates and are able to pass from the deposits into the bulk flow when there are changes in hydraulic conditions in the distribution system. These particles can deteriorate the quality of transported drinking water. 


\section{Formation of disinfection by-products}

The possible formation of disinfection by-products by reacting with chlorine was studied in the laboratory experiments under controlled conditions (temperature $20{ }^{\circ} \mathrm{C}$, residence time 72 hours, chlorine doses $0.5-4.0 \mathrm{mg} \cdot \mathrm{l}^{-1}$, by chloramination constant addition of $\mathrm{NH}_{4}^{+} 0.5 \mathrm{mg} \cdot \mathrm{l}^{-1}$ ). Deposits from the shaft before WR Sv. Anna were used. Their characteristics were as follows: Content of suspended solids $346 \mathrm{mg} \cdot 1^{-1}$, TOC $7.46 \mathrm{mg} \cdot 1^{-1}$, $\mathrm{pH}$ 7.6. The experimental results are given in Fig. 4 .

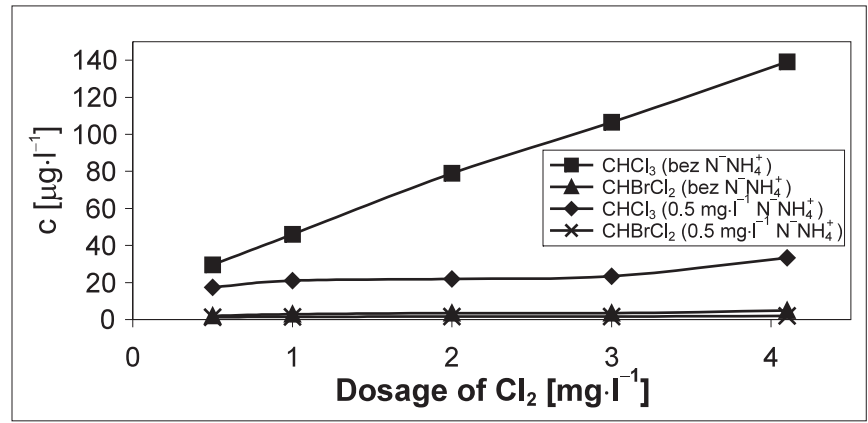

Fig. 4: Formation of THM in suspension with various doses of chlorine or chloramine

It was shown that the concentration of chloroform increased with increasing doses of chlorine from $15.4 \mu \mathrm{g} \cdot \mathrm{l}^{-1}$ (at $\mathrm{Cl}_{2}$ dose $0.5 \mathrm{mg} \cdot \mathrm{l}^{-1}$ ) to $77.7 \mu \mathrm{g} \cdot \mathrm{l}^{-1}$ (at $\mathrm{Cl}_{2}$ dose $4.0 \mathrm{mg} \cdot \mathrm{l}^{-1}$ ) whereas during chloramination with the same chlorine doses the THM content ranged from $11.5 \mu \mathrm{g} \cdot \mathrm{l}^{-1}$ to $14.1 \mu \mathrm{g} \cdot \mathrm{l}^{-1}$. This means that the increase in THM concentration was negligible.

\section{Conclusions}

The research has shown that the particles of deposits resuspended into the bulk flow during changes in hydraulic conditions in the distribution system can be a real source of THM and HAA. Formation of these compounds depends mainly on the concentration of resuspended particles in water, doses of chlorine, and reaction time.

\section{Acknowledgements}

This research has been supported by GAČR grant No. 103/99/0659 and by Research program CEZ: J04/98211100002. The authors would like to thank prof. V. Janda, doc. N. Strnadová and MSc P. Fišar from the Department of Water Technology and Environmental Engineering VŠCHT Prague for their assistance.

\section{References}

[1] Kiéné, L., Lu, W., Lévi, Y.: Relative Importance of the Phenomena Responsible for Chlorine Decay in Drinking Water Distribution Systems. Wat. Sci. Tech., Vol. 38, 1998, pp. 219-272

[2] El-Shafy, M. A., Grünwald, A.: THM Formation in Water Supply in South Bohemia, Czech Republic. Water Res., Vol. 34, No. 13/2000, pp. 3453-3459

[3] Vasconcelos, J. J. et al: Kinetics of Chlorine Decay. Journal AWWA, Vol. 89, No. 7/1997, pp. 54-65

[4] Ozdemir, O. N. et al: Realistic Numerical Simulation of Chlorine Decay in Pipes. Water Res., Vol. 32, No. 11/1998, pp. 3307-3312

[5] Grünwald A. et al: Effect of Deposits on Water Quality in Distribution System (2000). CTU Reports, Proceedings of WORKSHOP 2000, Part B, Vol. 4, No. 7/2000, p. 568

Prof. Ing. Alexander Grünwald, CSc.

grunwald@fsv.cvut.cz

Ing. Bohumil Št’astný

stastny@fsv.cvut.cz

Ing. Kateřina Slavíčková

slavickova@fsv.cvut.cz

Ing. Marek Slavíček

slavicek@fsv.cvut.cz

Department of Sanitary Enginee

ringCzech Technical University in Prague

Faculty of Civil Engineering

Thákurova 7, 16629 Praha 6, Czech Republic 